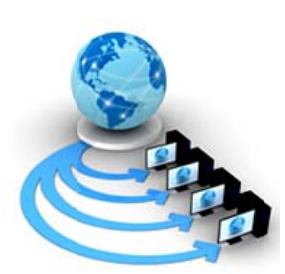

Volume 9, No. 1, January-February 2018

International Journal of Advanced Research in Computer Science

RESEARCH PAPER

Available Online at www.ijarcs.info

\title{
A NOVEL INITIAL BASIC FEASIBLE SOLUTION METHOD FOR TRANSPORTATION PROBLEM
}

\author{
Surjit Paul \\ Department of CSE, NIT Jamshedpur, \\ Jharkhand, India
}

\begin{abstract}
One of the popular operation research problems is transportation problem. Its solution is basically divided into two parts. Initially Initial Basic Feasible Solution (IBFS) is obtained then the result is used to calculate the optimal solution. The popular methods to find IBFS of transportation problem are North West Corner Method (NWCM), Least Cost Method (LCM), and Vogel's Approximation Method (VAM). In this paper, a novel approximation method is proposed to find out the IBFS of the transportation problem. There are five different examples used for which the IBFS are calculated using NWCR, LCM, VAM, and our proposed method. The results show that the proposed method provides the best result among them.
\end{abstract}

Keywords: Transportation problem, IBFS, NWCM, LCM, VAM.

\section{INTRODUCTION}

There are many problems discussed in operations research and Transportation problem is one of the widely used problems discussed in linear programming problem of operation research which is directly used in our day to day logistics and supply chain activities. It helps to solve problems related to distribution and transportation of resources from various sources to destinations so that the cost of transportation should be optimal for the commodity. The units of resources to be supplied from source to destination are the primary objective so that the cost of transportation should be minimal and profit should be maximum.

Let $x_{i j}$ be the quantity transported from the source $i$ to the destination $\mathrm{j}$. The problem is mathematically formulated as follows:

$$
\text { Minimize } \mathrm{Z}=\quad \mathrm{C}_{\mathrm{ij}} \mathrm{x}_{\mathrm{ij}}
$$

Subject to,

And,

$$
\begin{aligned}
\mathrm{ij} & =\mathrm{a}_{\mathrm{i}} \\
\mathrm{ij} & =\mathrm{b}_{\mathrm{j}}
\end{aligned}
$$

Where,

$$
\mathrm{x}_{\mathrm{ij}} \geq 0 \text { for all } \mathrm{i} \text { and } \mathrm{j} \text {. }
$$

$\mathrm{Z}$ : Objective function is minimize the total transportation cost.

$$
\mathrm{C}_{\mathrm{ij}} \text { : Transportation cost per unit from source } \mathrm{i} \text { to }
$$
destination $\mathrm{j}$.

$\mathrm{x}_{\mathrm{ij}}$ : Units of commodity sent from source $\mathrm{i}$ to destination $\mathrm{j}$.

$a_{i}$ : Quantity supplied from source $i$.

$\mathrm{b}_{\mathrm{j}}$ : Quantity demanded at destination $\mathrm{j}$.

Transportation problem is balanced if Supply

Demand

Otherwise unbalanced if Supply $\quad$ i $\quad \neq$ Demand

When number of rows are multiplied with number of columns then total number of variables are used in the transportation problem is obtained i.e. $\mathrm{mn}$. The total number of constraints for the transportation problem is $m+n$. For feasible solution the total number of allocations should be $(\mathrm{m}+\mathrm{n}-1)$.

The organization of the paper is as follows: section II deals with literature review; section III deals the proposed approximation method; section IV deals with results analysis and finally section $\mathrm{V}$ concludes the paper.

\section{LITERATURE REVIEW}

One of the most important problems discussed in operations research is the transportation problem. It deals with the transportation of some products from source to destination so that cost of transportation should be minimal and also satisfy the constraints related to demand and the supply. Transportation problem can be utilized in inventory, assignment, traffic, and so on. Transportation problems are required for analyzing and formulating such models [1-2]. Therefore primary objective of transportation problem is to find out the IBFS [3-4]. To obtain optimal solution requires start from the IBFS. Therefore IBFS affects the optimal solution of the transportation problem. In fact, we can say that finding IBFS would be significant to obtain optimal solution. There are only few methods available which can be used to find IBFS of the transportation problem [5-7]. The names of the methods are as follows: NWCM [8, 9], LCM [8, 9], and VAM [8-10]. In NWCM, the process begins from the northwest corner cell in the transportation table. In LCM, a cell having lower cost is selected sooner than a cell with higher cost. In fact, the process starts with the cell having the least cost of the transportation table. Most of the cases the LCM find IBFS better than NWCM because algorithm uses costs during the allocation unlike LCM. In LCM, all processes used in NWCM are repeated the only difference is that cell having minimum cost is selected first instead the northwest cell. VAM [11] is based on rows and column penalty where difference between two lowest cell costs for each rows and columns is considered as 
penalty to initiate the process. It is the best among LCM and NWCM.

\section{NOVEL APPROXIMATION METHOD}

The step by step process of the proposed method is given below:

Step1. Subtract elements of each row with the least element of each row.

Step2. Subtract elements of each column with the least element of each column.

Step3. Calculate the distribution indicators by subtracting the smallest and next-to smallest element of each row and each column of the reduced matrix and write them just after and below of the supply and demand amount respectively.

Step4. Identify the highest distribution indicator, if there are two or highest indicators then choose the highest indicator along which the smallest value presents in the cell. If there are two or more smallest elements present in the cells, choose any one of them arbitrarily.

Step5. Allocate $X_{i j}=\min \left(a_{i}, b_{j}\right)$ on the left bottom of the largest element in the (i, j)th cell of the reduced matrix.
Step6. If $a_{i}<b_{j}$, leave the ith row and readjust $b_{j}$ as $b_{j}{ }^{\prime}=b_{j}-a_{i}$. If $a_{i}>b_{j}$, leave the $j$ th column and readjust $a_{i}$ as $a_{i}=a_{i}-b_{\mathrm{j}}$. If $a_{i}=b_{j}$, then leave both the ith row and jth column.

Step7. Repeat step 4 to step 6 until the demand and supply requirement are exhausted.

Step8. Put all the allocations of the positive allocated cells of the reduced matrix to the original transportation table and calculate the total transportation cost.

Where,

$$
\text { Minimize } \mathrm{Z}=\sum_{i=1}^{m} \sum_{j=1}^{n} \mathrm{C}_{\mathrm{ij}} \mathrm{x}_{\mathrm{ij}}
$$

$\mathrm{X}_{\mathrm{ij}}$ is the total allocation of the $(i, j)$ th cell and $\mathrm{C}_{\mathrm{ij}}$ is the corresponding unit transportation cost.

\section{RESULTS ANALYSIS}

For verifying results of the proposed algorithm five examples are considered. The IBFS for each of the five examples are calculated using NWCR, LCM, VAM, and the proposed method.

\section{Example1:}

\begin{tabular}{|c|c|c|c|c|c|c|}
\hline \multirow{5}{*}{ 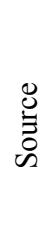 } & & \multicolumn{4}{|c|}{ Destination } & \multirow[b]{2}{*}{ Supply } \\
\hline & & D1 & $\mathrm{D} 2$ & D3 & D4 & \\
\hline & $\mathrm{S} 1$ & 20 & 22 & 17 & 4 & 120 \\
\hline & $\mathrm{S} 2$ & 24 & 37 & 9 & 7 & 70 \\
\hline & S3 & 32 & 37 & 20 & 15 & 50 \\
\hline & & 60 & 40 & 30 & 110 & 240 \\
\hline
\end{tabular}

NWCR=3680 LCM=3670 VAM=3520 Proposed Method=3460

Example2:

\begin{tabular}{|c|c|c|c|c|c|c|}
\hline \multirow{5}{*}{$\begin{array}{l}\mathscr{D} \\
\mathscr{0} \\
\mathscr{D}\end{array}$} & & \multicolumn{4}{|c|}{ Destination } & \multirow[b]{2}{*}{ Supply } \\
\hline & & D1 & $\mathrm{D} 2$ & D3 & D4 & \\
\hline & $\mathrm{S} 1$ & 10 & 22 & 15 & 4 & 120 \\
\hline & $\mathrm{S} 2$ & 18 & 27 & 5 & 9 & 70 \\
\hline & $\mathrm{S} 3$ & 32 & 37 & 24 & 15 & 50 \\
\hline \multicolumn{2}{|c|}{ Demand } & 60 & 40 & 30 & 110 & 240 \\
\hline
\end{tabular}

NWCR=3120 LCM=3210 VAM=2820 Proposed Method=2820

Example3:

\begin{tabular}{|c|c|c|c|c|c|c|}
\hline \multirow{5}{*}{$\begin{array}{l}\mathscr{\delta} \\
\stackrel{0}{0} \\
\tilde{O}\end{array}$} & & \multicolumn{4}{|c|}{ Destination } & \multirow[b]{2}{*}{ Supply } \\
\hline & & D1 & D2 & D3 & D4 & \\
\hline & $\mathrm{S} 1$ & 4 & 19 & 22 & 11 & 100 \\
\hline & S2 & 1 & 9 & 14 & 14 & 30 \\
\hline & $\mathrm{S} 3$ & 6 & 6 & 16 & 14 & 70 \\
\hline \multicolumn{2}{|c|}{ Demand } & 40 & 20 & 60 & 80 & 200 \\
\hline
\end{tabular}

NWCR=2820 LCM=2090 VAM=2170 Proposed Method $=2090$ 
Example4:

\begin{tabular}{|c|c|c|c|c|c|c|c|}
\hline \multirow{6}{*}{$\begin{array}{l}0 \\
\stackrel{0}{0} \\
\tilde{D} \\
\mathscr{n}\end{array}$} & & \multicolumn{5}{|c|}{ Destination } & \multirow[b]{2}{*}{ Supply } \\
\hline & & D1 & D2 & D3 & D4 & D5 & \\
\hline & S1 & 10 & 8 & 9 & 5 & 13 & 100 \\
\hline & S2 & 7 & 9 & 8 & 10 & 4 & 80 \\
\hline & S3 & 9 & 3 & 7 & 10 & 6 & 70 \\
\hline & S4 & 11 & 4 & 8 & 3 & 9 & 90 \\
\hline \multicolumn{2}{|c|}{ Demand } & 60 & 40 & 100 & 50 & 90 & 340 \\
\hline
\end{tabular}

NWCR=3010 LCM=2070 VAM=2130 Proposed Method $=2150$

\section{Example5:}

\begin{tabular}{|c|c|c|c|c|c|c|}
\hline \multirow{6}{*}{ 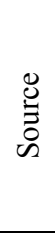 } & & \multicolumn{4}{|c|}{ Destination } & \multirow[b]{2}{*}{ Supply } \\
\hline & & D1 & D2 & D3 & D4 & \\
\hline & S1 & 7 & 5 & 9 & 11 & 30 \\
\hline & $\mathrm{S} 2$ & 4 & 3 & 8 & 6 & 25 \\
\hline & S3 & 3 & 8 & 10 & 5 & 20 \\
\hline & S4 & 2 & 6 & 7 & 3 & 15 \\
\hline \multicolumn{2}{|c|}{ Demand } & 30 & 30 & 20 & 10 & 90 \\
\hline
\end{tabular}

\section{NWCR=540 LCM=435 VAM=470 Proposed Method $=410$}

\section{CONCLUSION}

The proposed novel method for finding IBFS provides the best solution among NWCR, LCM and VAM in most of the cases. Also the algorithm complexity is reasonable due of fewer calculations in the algorithm; only rows and column operations have to be done like minimize assignment problem. Therefore, we may say that this method may be used in future works in real transportation problems. Finally, this method only evaluate the IBFS but finding optimal solution better than Modified Distribution Method (MODI) is not found in the literature. In future, a novel algorithm will be proposed for obtaining optimal solution.

\section{REFERENCES}

[1] L. Aizemberg, H.H. Kramer, A.A. Pessoa, E. Uchoa, "Formulations for a problem of petroleum transportation", European Journal of Operational Research, Vol. 237,
Issue 1,
2014 pp.
$82-90$. https://doi.org/10.1016/j.ejor.2014.01.036.

[2] S. Juman, M.A. Hoque, M.I. Buhari, "A sensitivity analysis and an implementation of the well-known Vogel's approximation method for solving an unbalanced transportation problem", Malaysian Journal of Science, Vol. 32, No. 1, 2013, pp. 66-72.
The Figure 1 shows the comparative graph of IBFS results using NWCR, LCM, VAM, and the proposed method of the five examples considered for the evaluation. From Figure1, it can be depicted that the proposed method outperforms than NWCR, LCM, and VAM. The transportation cost of the proposed method is minimum.

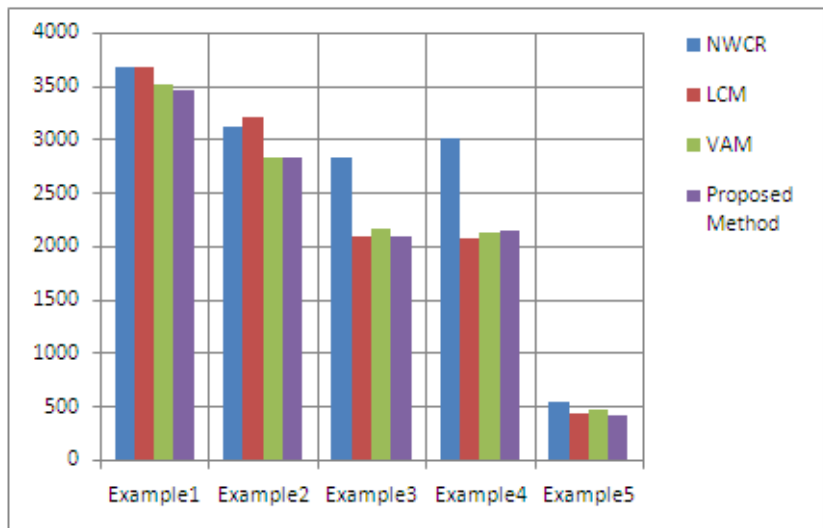

Figure 1 Comparison among NWCR, LCM, VAM, and Proposed Method

[3] N.M. Deshmukh, "An Innovative method for solving transportation problem", International Journal of Physics and Mathematical Sciences, Vol. 2 , No. 3, 2012, pp. 8691.

[4] S.Z. Ramadan, I.Z. Ramadan, "Hybrid two-stage algorithm for solving transportation problem", Modern Applied Science, Vol. 6, No. 4, 2012, pp. 12-22.

[5] Z.A. Juman, M.A. Hoque, "An efficient heuristic to obtain a better initial feasible solution to the transportation problem", Applied Soft Computing, Vol. 34, 2015, pp. 813-826. https://doi.org/10.1016/j.asoc.2015.05.009.

[6] U.K. Das, M.A. Babu, A.R. Khan, M.A. Helal, M.S. Uddin, "Logical development of Vogel's approximation method (LD-VAM): an approach to find basic feasible solution of transportation problem", International Journal of Scientific \& Technology Research, Vol. 3, No. 2, 2014, pp. $42-48$.

[7] S. Korukoglu, S. Balli, "An improved Vogel's approximation method for the transportation problem", Mathematical and Computational Applications, Vol. 16, No. 2, 2011, pp. 370-381, https://doi.org/10.3390/mca16020370.

[8] A.T. Hamdy, "Operations Research: An Introduction". 8th Edition, Pearson Prentice Hall, Upper Saddle River, 2007.

[9] G.C. Ray and M.E. Hossain, "Operation Research", Bangladesh, 2007, 103-104.

[10] N.V. Reinfeld and W.R. Vogel, "Mathematical Programming", Prentice-Hall, Englewood Cliffs, 1958.

[11] H. H. Shore, "The Transportation Problem and the Vogel Approximation Method", Decision Sciences, Vol. 1, Issue 3-4, 1970, pp. 441-457. 